\title{
An Investigation of the Extent of the Establishment And Utilization of Guidance And Counseling Departments in Secondary Schools in Mwingi West Sub-County, Kitui County
}

\author{
Evelyne M. Mwendwa \\ DIp G/C BED, MED, PHD (Pursuing) \\ Maasai Mara University, P.O. Box $861-(20500)$ Narok. \\ Email: mwendwaevelyne60@gmail.com (corresponding e-mail) M: +254725327037 \\ DOI: $10.31364 / \mathrm{SCIRJ} / \mathrm{v} 8.18 .2020 . P 0820791$ \\ http://dx.doi.org/10.31364/SCIRJ/v8.i8.2020.P0820791
}

\begin{abstract}
Most of the modern countries are faced with so many challenges in both education and economy. These challenges have brought a lot of problems to different people at different developmental stages. This sums up that secondary school students are also affected. Most of the times, they find themselves acting illegally towards the school rules and regulations hence colliding with the teachers. They are emotionally and psychologically affected resulting into the students' "unrest" most of the times. Therefore Guidance and Counselling has become necessary for preventing and alleviating such above mentioned problems. To make this a success, it is important to have Guidance and Counselling departments established, developed and utilized in all secondary schools. The study intended to investigate on the extent of the establishment and the utilization of Guidance and Counselling programmes in secondary schools in Mwingi West sub-count Kitui County. First, the researcher sought permission from ministry of education, the Sub- county Educational officer Mwingi West sub-county. After been authorized by the principals of the selected schools to conduct the study in their schools, the researcher used the simple random sampling to select the sixty (60) students from the selected schools. To select the principals and the teachers was easy; it only involved the principals and the counselor teachers of the selected schools. The researcher administered the questionnaires to the principals, teachers and the students personally.The Researcher interviewed all the respondents in turns for more information. The sample of the study included boys' boarding schools, girls' boarding schools, mixed boarding schools, and mixed day schools. The sampling methods were simple random sampling and stratified sampling. The study used survey research design to collect data. The instruments of data collection comprised of questionnaires and the interviews The results findings showed that there was a positive establishment of the guidance and the counseling departments in almost every school and the guidance and the counseling service was been utilized.The findings also showed that there was a positive perception of the principals, teachers and the students towards the guidance and the counseling service.
\end{abstract}

Key Words: Unrest, establishment, principal, perception

\section{Introduction}

A fruitful welfare, progress and happiness of any country depend on the optimal contribution made by each individual towards the country. Therefore each individual should be helped and assorted fully to explore and discover his/her potentiality. The individual should also be assisted to understand himself /herself in a realistic manner. This will help the individual to join in a more careful manner in the development of the entire country. The help should be given to the individual at any stage of development. Most care should be taken especially into those in the adolescent stage. This stage is a present and future - oriented period of testing. It has been marked by physical and emotional changes and heightened emotionality. Adolescents are idealistic, self - critical, and very critical of hypocrisy and phoniness in others. They become reactive when adults refuse to listen to them. They also react when adults do not provide meaningful participation in solving their problems. This stage of dilemma begins in primary schools. The fortunate ones have had models and have learned to copy the models' behaviors selectively. Others may have had guidance and counseling in primary school level. More than ever before, counselor educators must screen prospective counselors with the greatest care. They need to develop for them the best possible programs. A properly well-guided pupil or student will perform better in his/her examination. Behavior modification can be accorded through guidance and counseling. Those who lack these may develop maladjusted behaviours. This in turn may lead to students' unrest. In some secondary schools, there are well established guidance and counseling departments. Those departments are assigned to counselor teachers who offer guidance and counseling services. However, in spite of there being 
guidance and counseling departments in our secondary schools, there is a continuous problem of the student's indiscipline in most of the secondary schools in the sub-county. The ministry of education, science and Technology recognizes guidance and counseling as an essential service. A service to be offered to all learners in Kenya. The ministry has attempted to implement this, for example, the Gachathi report (1976), the National Committee on Educational Objectives and Policies (NCEOP) recommended that, all teachers should take compulsory course in guidance and counseling as part of their training. This is being implemented in teacher training colleges. It is done through professional studies and educational programmes in the universities. Presidential working party, on Education and Manpower Training for Next- Decade and beyond, (1998) recommended that, schools and colleges should establish guidance and counseling departments and seniors teachers should be made responsible. Many schools and colleges have people to coordinate guidance and counseling. In some of our Secondary schools, there are well - established guidance and counseling departments. However in order for guidance and counseling to have an impact in schools, it should be positively perceived. The fact that perception of principals, teachers, and students are crucial to the effective implementations of any new schools programme it has been studied elsewhere (Ogachi, 1995).The underlying logic is that one's perception influences his/her positive attitudes and input to the success of the programme. The guidance and counseling programme in any secondary school will flourish only when the administration recognizes and supports its objectives. It sets the "tone" or provides the climate in which the guidance and counseling Programme can be propagated.

Due to this, the researcher decided to investigate on the extent of the establishment and utilization of guidance and counseling programmes in secondary schools in Mwingi West sub- County. The investigation was also prompted by the fact that some secondary schools had experienced major problems like strikes, indiscipline, arson, drug abuse, poor performance in K.C.S.E, and anti-social behaviors. According to Siringi (2003), "unrest" in schools is blamed on drugs" (p, 11). Cases of students injuring each other in fights after taking drugs are common in our secondary schools (1999).A tragedy occurred recently, when Ngenda secondary school was burnt in 2004. This makes one wonder where the extent of the establishment and utilization of guidance and counseling programmes, has reached and what it has done. Guidance and counseling should provide services that encourage the moral growth and psychological maturity of our students (Wanjohi 1990). The perception of school principals and teachers towards guidance and counseling service is essential to determine the extent of the establishment and utilization of guidance and counseling service in Secondary schools.

\section{Statement of the problem}

Guidance and the counseling departments have been established in most of our secondary schools and they offer guidance and the counseling services to the students.Inspite of the presence of these counseling services, the problem of indiscipline continues to exist in most of our secondary schools. For instance, there have been reported cases of drug abuse among our students, arson and school strikes (Ndung'u, 2002).problems of indiscipline in our secondary schools could have been caused by external and internal factors. The external factors could include drug pushers especially in the urban schools. However, internal factors are the ones of immediate concern in this study, since they are the ones that the principals and the teachers can manipulate acceptable levels of discipline. Some of the internal factors could include bad school traditions where indiscipline has been allowed to grow without any serious concerted effort to eradicate it. In addition, some of the secondary school administrators and teachers do not support guidance and the counseling departments in their schools. On the other side, the parents expectations is that, total guidance and counseling should be provided at school without the maximum contribution of the parents. This implies that the school principals and the teachers are left with the sole responsibility of ensuring that the students are well disciplined. Therefore, to minimize the effects of internal factors contributing to students' indiscipline, the principals and the teachers need to have a positive perception of the guidance and the counseling service through establishing the guidance and the counseling services in all the schools and supporting them. Little has been done to establish the perception of the principals and the teachers' perception towards the guidance and the counseling service and how far the guidance and the counseling departments have been established and their utilization in the secondary schools. This research seeks to examine the far the guidance and the counseling departments have gone and how the principals and the teachers perceive the guidance and the counseling service in their schools.

\section{Justification of the study}

This study is considered important because of the following reasons. First, there is a problem of indiscipline in secondary schools in Mwingi West sub- County and the current trend shows that the problem is increasing now and then. This problem has already become a National Agenda. This study seeks to find appropriate and suitable solutions to this problem. Secondly, for any effective strategies 
to be designed to address indiscipline in secondary schools, relevant and accurate information is necessary. The findings of this study can be important in this regard. It can also provoke further research in this area, thus providing enough information to address the indiscipline in the schools. Thirdly, this research is also justified by the fact that it is timely. Indiscipline in secondary schools is increasing both in quantity and the degree of the consequences is has not been discovered. This calls for a radical review of the role of the principals and teachers in relation to the establishment of the guidance and the counseling departments. The principals and the teachers play a great role as the guarantors of the safety of the students since they are under their care. This proves it right that this study will play a great role pertaining this issue.The research findings and the recommendations are expected to be useful to the educational stake holders for instance the secondary school principals and the teachers, educational officers and the curriculum developers as the study will guide them in their strategic plans and developing of the educational policies.

\section{Significance of the Study}

1. The significance of the study rests on the fact that the research added to the existing knowledge on guidance and counseling service in secondary schools in Kenya

2. The researcher is able to make recommendations that will be able to assist the principals and the education administrators to have a positive perception towards guidance and counseling service.

3. The results of this study will assist the educational policy makers to lay down good policies as pertains guidance and counseling service in schools.

4. The results of this study can become a base for further research on this subject matter. The results may inspire other academicians to develop the desire of doing research in this area and do further studies to solve problems related to students' indiscipline, hence it will result into improvement in the education sector.

\section{Conceptual Framework}

The conceptual framework is derived from theories of the study highlighting the extent of the establishment of the guidance and counseling departments as well as the perception of the principals' and the teachers' perception towards the guidance and the counseling service.Conceptualy,the study was based on the belief that in order to investigate on the establishment of the guidance and the counseling departments it was essential to understand the principals' and the teachers perception towards the counseling service. In order to develop a better understanding of the perception of the secondary school principals' and the teachers' perception towards the guidance and the counseling service, greater emphasis needs to be given to the ways in which the latter understand their social and cultural processes that help them make sense of guidance and counseling service. In this study, the perception of the principals and the teachers may be positive or negative toward guidance and the counseling service; this plays a great role of the establishment of the guidance and the counseling departments in the secondary schools.

This conceptual approach emphasized the earlier theories mentioned that operate in particular secondary school principals and teachers. It focused on the processes through which identies (the perception of the principals and the teachers)were acquaired,developed and maintained and on the way in which meanings about guidance and counseling service were communicated and learned. This eventually may result in either the success or minimal success in offering guidance and counseling service in our secondary schools.

\section{Guidance and Counseling Service}

Dowing,(1968) has defined guidance service as organized set of specified services established as an integral part of the school environment, designed to promote the development of students and assist them towards realization of sound, wholesome adjustment and maximum accomplishments according to their potentialities. In U.S.A.Where guidance service is provided in all educational institutions, the Programme is normally organized into four main sections: the appraisal service, an information service, the counseling service and a planning, placement and follow-up service. Dowing, (1968) condenses the varied statements of many authorities regarding guidance and the counseling service into six categories and devotes a chapter to each:

1. Pupil inventory (records and cumulative folders\}

2. Pupil appraisal through testing 
3. Counseling service

4. Counseling as the integration of various service

5. Educational and vocational information

6. Placement and follow-up

Guidance service is concerned with helping the individual to weigh and evaluate his/her personal assets and liabilities in relation to the opportunities and requirements of occupation that interest him or her, and make plans that are based on resulting decisions (Myers, 1941).It involves knowledge on the part of the counselor both of the individuals assets and liabilities and of possible courses of action open to him/her. It consists of an interview or series of interviews between the counselor and the one counseled, in which sincere and frank efforts are made to face the facts that should determine decisions and plans.

\section{Methodology}

This article is based on methods and procedures that guided the study .It is divided into seven sub- headings. Research designs, population, sampling instrumentation, pilot study, data collection and data analysis. It was conducted as a survey research. It may attempt to describe what currently takes place in a social system just like a school. (Julian, 1962). It also points at future needs (Mouly, 1970).The researcher used interview method that allowed her to create relationship between her and the respondents during different interview schedules. The researcher obtained an introduction letter from the school of post graduates Kenyatta University which allowed her to be given the authorization permit from National Committee for Science Technology and Innovation (NACOSTI), which allowed her to proceed to the Education County Director, Kitui County to seek permission to visit the selected schools. At any school the researcher arrived to conduct the interview, she introduced herself the research, as well as the reasons for conducting the study so as to establish rapport between her and the respondents. She was physically present and as they responded to the interview questions she was able to get their feelings and get their non- verbal communication that confirmed their feelings and what they said. The researcher was able to clarify some areas where the respondents did not understand. The researcher viewed the interview method of data collection as the most effective method for data collection because she was able to collect a large data in a short period and it was less cost full and she was also able to combine the results of the observations she got from the respondents with the ones of the interviews to get a comprehensive information. Other advantages of the interviews are the spontaneity of information and flexibility. The researcher felt a sense of security due to the fact that every data was collected in face-to face situation (McLeod, 19980).

To investigate on the establishment of the school counseling departments in mwingi West sub- County, the researcher used two groups, the teachers and the students. The subjects were selected from ten schools in mwingi west sub- County. This research was conducted between July and September 2006.To get the sample size of the schools, teachers and the students, the researcher used stratified and simple random sampling. To select the schools, a list of all secondary schools in mwingi West sub-County was obtained from the TSC Sub-County Administrator mwingi -West. Only public schools were involved since the investigation was basically based on the public schools only. From the list, schools were categorized into boys' and girls' boarding and mixed and day schools. To select the teacher's sample, the researcher asked the principlas of the sampled schools to avail their register of the teachers who were present on that day of the research visit. The researcher did random sampling that involved writing down the names of the teachers on the pieces of papers eventually putting them in one container and shaking the container to make sure that they were completely mixed. The researcher picked a quarter of the total number of the teachers in each school .These in turn became the representative sample of the teachers in each school. To sample the students, random sampling was also used. The names of all the form three students were written in individual separate papers and put in a container. Ten papers were picked from every school .These in turn became the representative sample in their schools.

\section{Research Variables}

The independent variables of the study are namely:

. Type of school (mixed schools, boarding, boys' or girls')

. Gender considerations, either male or female students.

. Guidance and Counselling programmes. 
The dependent variables comprise:

The extent of establishment and utilization of Guidance and Counseling programmes and teachers' perception

\section{Location of the Study}

The study was carried out in Mwingi West sub- County in the Republic of Kenya. The choice of Mwingi west sub-county was necessitated by the following reasons. Mwingi West sub- county Secondary Schools were not spared the spate of students' strikes and other social malpractices in schools that are used to show students' unrest in Kenya. The researcher had also noted the problem of girl student pregnancies and boys taking drugs which are a common social problem among most schools in Mwingi West sub- County. When the school administration measured to curb these problems, the students tended to riot.

\section{Physical and Administrative Description}

Mwingi West sub- county is made up of five wards namely Kyome/ Thaana Ward which covers an area of approximately308, 00 square kilometers and a population of approximately22, 443 people.Nguutani Ward covers an area of 209 square kilometers and has a population of approximately 27, 265 people.Migwani ward covers an area of 685.10 kilometers and has a population of 28169 people. Kiomo/Kiethani Ward covers approximately an area of 358.40 square kilometers and has a population of 21,000 people. Central Ward has a population of 23,743 people and it covers an area of 107.8 kilometers. Mwingi west constituency has a population of 1222,620 people and it covers an area of 1,669 square kilometers.one of the thirteen districts that make up Eastern Province in the Republican of Kenya. Migwani Division is one of the nine divisions of Mwingi West sub- county boarders Kithyoko in Machakos County to the west, Kabati sub-county in Kitui- west consistency to the south, Mutitu sub-county in Kitui to the South - east, and Central Division to the north.

\section{Economic potential}

The main source of income in Mwingi West sub- County is small scale farming. The main crops grown are Maize, beans, sorghum, millet, peas and green grams. Most of the women involve themselves in baskets (syondo) making. Both men and the women involve themselves in rope making. The above two activities are usually practiced when rain fails in the county. This help the people to get their daily bread and it also keep them busy during the dry season. It is also a source of income in which people get money for the school fees. However, there are also some small-scale industry mainly seen in form of jua kali activities such as metal work and woodwork

\section{Ethical Considerations}

The respect for the basic rights of human and animals is a fundamental obligation to all researchers (Zimbardo, 1966). It was with this in mind that the researcher sought clearance to carry out the research from the National Council for science and Technology that is based at the Ministry of Education, after approval from Kenyatta University Institute of Open learning. Once in the field, further clearance was obtained from the Mwingi west sub- county Commissioner and the sub- county Education officer. Further permission was sought from principals of the sampled schools before the administering of the questionnaires. The participation in the study was voluntary. To ensure anonymity and secure privacy of the participants, the researcher did not require names and other means of identifying participants during the research. No identification number was required to be given in the questionnaires before their return. This helped the participants to feel free and created trust in the researcher. All the principals were informed of the confidentiality during the data collection. The researcher ensured that all the information to be obtained would only be used for the study

\section{Findings}

It was found that students preferred non-teacher counselors. when interviewed the students said that they had no trust in their teacher counselors because they were likely to tell other teachers the students' secret issues while in the staffroom. It was also found that most principals, teachers and students believed that guidance and counseling was a very important service and that it was not a mere waste of time though it was confused with discipline. They contended that it was not fully developed and utilized in their schools. It was also found that majority of the schools had the counseling departments and untrained teachers for counseling and individual 
counseling was not fully utilized since the students did not have confidence in their counselor teachers. It was also found that most schools did not have trained counselors thus there was no professionship in counseling. In some schools, there were no counseling offices hence counseling was done in any private area within the school compound. Guidance and counseling was perceived as an important tool that helps in administration.

\section{Conclusions}

The study that was carried out revealed that all secondary schools were aware of guiding and counseling services. They knew what benefits accrued to this hence could totally avoid it. They were aware that it is the Ministry of Education's requirement, that guidance and counseling should be established and utilized .However due to various constraints, efforts to have the services fully delivered were not successful. The respondents agreed that the counselor teachers were not professionally trained in guidance and counseling .This could be one of the factors hindering a successful delivery of guidance and counseling services. Teachers may wish to help the students but lack the relevant skills, resources, and adequate time The whole scenario is a haphazard organization of what the guidance and counseling programme might entail. Students were also in dire need of these services but they did not receive them to their satisfaction. There are recommendations that may improve the delivery of guidance and counseling services to students. Most schools had established guidance and counseling offices but they were not aware of how to use them because they lacked trained personnel in their schools. In most schools, the principals viewed the guidance and counseling service as a very important tool and should be timetabled like any other subject. There was no doubt that majority of the school principals and teachers felt that guidance and counseling was an essential component of school curriculum activity though it was confused to be a disciplinary service. The positive perception of the principals, teachers and the students towards guidance and counseling did not lead to proper establishment of the guidance and the counseling departments but it required government's and the ministry's support.

\section{Implications}

Positive perception of guidance and counseling amongst the secondary school principals, teachers and the students should be marched with practical implementation of guidance and the counseling service to see its full success in our secondary schools. This can successfully be acquired through the establishment of the guidance and the counseling departments in all the secondary schools in the county. This would involve diversification of guidance and counseling services, training of all principals and teachers on guidance and counseling, and more allocation of time and resources to guidance and counseling service was required.

\section{RECCOMMENTANTIONS}

* Out of sixteen secondary schools in Mwingi West sub-county only (38\%) of the schools were involved in the study .It is therefore recommended that another research be carried to cover all the schools in the sub -county ,and if possible the whole kitui county.

Majority of the students preferred non-teacher counselors. When interviewed, the students said that they had no trust in their teacher counselors. The reason could be lack of enough skills in handling guidance and counseling service by the teachers, as majority of the respondents responded that, majority of the counselor teachers were not trained. It is therefore recommended that all the counselor teachers be trained and be allowed to attend guidance and counseling seminars and refresher courses.

* Majority of the respondents reported to have established departments of guidance and counseling. However the rest reported not to have established these departments of guidance and counseling in their schools. It is therefore recommended that these departments be established in these schools. 
* Majority of the respondents agreed to have guidance and counseling offices in their schools. However the rest had no guidance and counseling offices in their schools. It is therefore recommended that, the offices be constructed and be equipped with the necessary materials for guidance and counseling in these schools.

* When interviewed, the principals said that the counselor teachers had the same workload as the other teachers and there was no specific time set for guidance and counseling and neither was it indicated in the timetable. It was recommended that, the workload for guidance and counseling teachers be reduced and if possible, be set time for guidance and counseling in all secondary schools in the sub- county.

* When interviewed, the respondents agreed that guidance and counseling was only remembered when an indiscipline problem arose in the school. It was therefore recommended that guidance and counseling services be a continuous process. It should never be sought when there is a problem in the school that threatens discipline. It should not be used as a means of getting information from students, since this makes them keep off from guidance and counseling seeking. Guidance and counseling should not be confused with discipline but should be taken as a tool that modifies behavior of an individual.

* When interviewed, the students said that, they had no trust with their teacher counselors, the teacher counselors could not keep whatever discussed between them and the students confidential. This could be the reason why individual counseling is not much utilized in schools in the sub-county. It is therefore recommended that, counselor teachers be made to sign a declaration indicating that they will keep whatever discussed between them and the students confidential.

* It was recommended that each school should have a counselor of its sex and a mixed school should have counselors of both sexes to meet the needs of both boys and girls.

* Majority of the schools had untrained counselors and did not have guidance and counseling offices in their schools .Therefore guidance and counseling offices should be established in all schools and counselor teachers be trained.

\section{Recommendation for future Research}

It should be observed that the scope of this study has been limited. Therefore, further research should be pursued. A similar study covering other sub counties in the whole county is required. This would help in the making of the general conclusions for the whole nation, after which measures towards improvement of guidance and counseling service would be undertaken fully. Another research on the perception of the school principals, teachers, students and the community towards guidance and counseling should be undertaken including the success or failure of the guidance and the counseling service. This observation would review whether there is any correlation between guidance and the counseling service and its progress in our secondary schools.

There is need to investigate on other external and internal factors besides the establishment of the counseling departments and perception for instance, parental influence, banning of canning in schools and the large workload of teaching that affect the secondary school principals and the teachers.

\section{REFERENCES}

Daily Nation (1996, June $19^{\text {th }}$ ). Truancy lowered standards of education in Mombasa Primary Schools.

Dowing L.N (1968). Guidance and Counseling: Introduction .New York: McGraw-Hill.

Gachathi, P.J. (1976). National Committee on education objectives and policies (Publication, No Adm. 901679).Nairobi, Kenya Government Printing Office.

Graff, R.W. and Warner, R.W. (1968).Cited by Coohran, J.R, and Peter, H.J. (1972) Guidance: An introduction Selected Reading Ohio.

Kamunge Report (1988). Presidential Working Party, on Education and Manpower training for next-Decade and beyond, adds.

Mahomey ,D.C (1973). The art of helping people affectively Association Press, New York. 
Mouly, G.J. (1970). The science of Education research ( $2^{\text {nd }}$ Ed.). New York: American Book Col.

Ndung`u, J.B. (2002). A study of the types of guidance and counseling services in the Municipality Division of Nyeri District-Unpublished Masters of Education Research Project Kenyatta University, Nairobi ,Kenya.

Njimu ,G. (2004).Perception of the secondary schools principals and teachers towards guidance and counseling Unpublished Masters Thesis ,Kenyatta University ,Nairobi ,Kenya .

Ridhaa, J.W. An investigation on the quality of guidance and counseling services in Udagani Secondary School.

Shertzer and Stone, (1966). Fundamentals of Counseling.

Siring, s. (2003, October 27 $\left.7^{\text {th }}\right)$. Unrest in schools blamed on drugs. Daily Nation, P. 11.

Tumuti , S. (2001) . Introduction to Guidance and Counseling. A training module of Kenyatta University.

Wanjohi, K. (1990). A study to investigate perceptions of the role of the counselors in secondary schools in Nyeri , Kenya, Unpublished Masters of Education Research Thesis , Kenyatta University ,Nairobi , Kenya. 